\title{
"Meu reino por um cavalo!": a construção da imagem vilanesca do rei Ricardo III a partir das crônicas de Holinshed, de $1587^{1}$
}

Renata Ribeiro Oliveira ${ }^{2}$

Resumo: Este artigo tem como objetivo analisar a construção da imagem de vilão do rei Ricardo III da Inglaterra, a partir das Crônicas de Holinshed, de 1587. A história do monarca, assim como seu caráter, são bastante discutidos na historiografia inglesa, sendo este constantemente retratado como um dos piores reis do país. Contudo, em muitos estudos, julgamentos de caráter são feitos a partir de atos atribuídos ao rei desde o século XVI, durante a dinastia Tudor, que retirou Ricardo do poder. As Crônicas foram uma das principais fontes históricas do período e responsáveis por criar um imaginário em torno do rei Plantageneta, caracterizando-o como assassino e vilão, sendo posteriormente imortalizado pela famosa peça de William Shakespeare, Ricardo III.

Palavras-chave: Ricardo III, Tudor, Crônicas de Holinshed.

Abstract: This article aims to analyze the construction of the image of villain of King Richard III of England, from the Chronicles of Holinshed, 1587. The history of the monarch, as well as his character, are much discussed in English historiography, him being constantly portrayed as one of the country's worst kings. However, in many studies, judgments of character are made from acts attributed to the king since the sixteenth century, during the Tudor dynasty, which removed Richard from power. The Chronicles were one of the main historical sources of the period and responsible for creating an ideal around the Plantagenet king, characterizing him as killer and villain, and later immortalized by the famous play of William Shakespeare, Richard III.

Keywords: Richard III, Tudor, Chronicles of Holinshed.

${ }^{1}$ Artigo elaborado para conclusão do curso de pós-graduação lato sensu em História Cultural, pelo Centro Universitário Claretiano, em 2015.

${ }^{2}$ Licenciada e bacharel em História pela Pontifícia Universidade Católica de Minas Gerais, especialista em História Cultural pelo Centro Universitário Claretiano e pósgraduanda em Língua Inglesa e Suas Literaturas, pela Estácio. renata_ro@outlook.com 
A história do rei inglês Ricardo III (1483-1485) ${ }^{3}$ recentemente tem sido destaque nas mídias e revistas especializadas. A descoberta de seus ossos, enterrados em um estacionamento na cidade de Leicester, na Inglaterra, em 2012, trouxe à tona uma discussão sobre a vida do monarca, seu reinado e detalhes de sua morte na Batalha de Bosworth, em $1485^{4}$. Parte do debate diz respeito a sua índole, o que faz com que figure frequentemente na lista de piores reis ingleses.

Essa imagem pejorativa se deve, principalmente, ao retrato do monarca nas Crônicas de Holinshed, de 1577/1587, utilizadas como fonte histórica por Shakespeare na peça Ricardo III, que perpetuou a figura de vilão, assassino, aquele capaz de cometer os piores atos para conseguir poder.

$\mathrm{O}$ presente artigo tem como objetivo desmitificar a figura do rei, contudo, sem isentá-lo de suas ações. Busca-se observar a validade dessas afirmações, de acordo com a metodologia histórica, ou seja, devidamente comprovadas. Questiona-se, portanto: até que ponto a construção da imagem de Ricardo III após sua morte deve-se a atos que realmente aconteceram ou a conjecturas sobre seu caráter? Ainda, quais foram as primeiras fontes que descrevem o monarca de modo depreciativo, contribuindo para a perpetuação desta imagem de Ricardo?

\footnotetext{
${ }^{3}$ As datas entre parênteses indicam o tempo de reinado.

4 Sobre a descoberta dos ossos, identificação e enterro do rei, ver http://www.kriii.com/
}

Revista Vernáculo n. ${ }^{\circ} 40$ - segundo semestre $/ 2017$

ISSN 2317-4021 
Para atingir tais objetivos, foi feita uma análise da fonte primária, as Crônicas, observando a construção da imagem de vilão feita pelos autores a respeito de Ricardo III, assim como uma identificação dos relatos utilizados por eles, uma vez que não presenciaram os fatos. Ainda, para entender o contexto histórico por trás da crônica, bem como a vida e o governo do rei, foram abordadas fontes bibliográficas atuais sobre o tema.

\section{O rei Ricardo III, as Guerras das Duas Rosas e a dinastia Tudor}

"Tal lorde é Lúcifer, quando ele
entra no coração de um príncipe
orgulhoso, dado à cobiça e
crueldade ${ }^{5 "}$ (HOLINSHED,
1587, n.p., tradução nossa)

Ricardo III nasceu em 1452, quarto filho de Ricardo Plantageneta, $3^{\circ}$ duque de York, e Cecília Neville, ambos descendentes de realeza. Possuíram territórios vastos na Inglaterra e constituíram uma das mais nobres famílias do país. Participaram ativamente nas Guerras das Duas Rosas, conflitos civis entre duas famílias nobres, os Lancasters e os Yorks, ambas reivindicando o trono inglês.

No século XIV, Henrique Bolingbroke, neto do rei Eduardo III (1327-1377) e duque de Lancaster, usurpou o trono de Ricardo II

\footnotetext{
5 "Such a lord is Lucifer when he is entered into the hart of a proud prince, giuen to couetousnesse and crueltie."
} 
(1377-1399), seu primo, por considerá-lo incapaz de governar devido às decisões políticas tomadas durante seu reinado. Assumiu o título de Henrique IV (1399-1413) e iniciou a época em que os Lancasters reinaram na Inglaterra. Nos períodos seguintes, seus descendentes Henrique V (1413-1422) e Henrique VI (1422-1461; 1470-1471) governaram o país, sendo Henrique V conhecido pela vitória na Batalha de Agincourt, em 1415, durante a Guerra dos Cem Anos ${ }^{6}$.

As disputas entre as duas famílias iniciaram a partir do momento em que Ricardo Plantageneta, pai de Ricardo III, considerou o reinado de Henrique VI ineficaz e reivindicou a coroa, pois acreditava ser sua descendência mais legítima que a do rei. Vários relatos descrevem Henrique como uma pessoa frágil, enferma, sem capacidade para governar a Inglaterra. Dan Jones explica sobre um dos períodos de doença do monarca:

Ele se tornou completamente indefeso, removido de raciocínio e do mundo em sua volta, ao ponto de total vacuidade. Ele não reconhecia ninguém. Ele não conseguia falar ou responder, de modo algum, as questões. Ele não conseguia se alimentar, nem se lavar sozinho, pois não tinha mais controle de seus braços e pernas, muito menos manter sua cabeça elevada. Ele não tinha noção de tempo. Nenhum médico conseguia animá-lo. Nenhum remédio poderia estimulá-lo. (...) Henrique estava simplesmente mudo e inerte: um real nada. Mesmo

${ }^{6}$ Conflito entre Inglaterra e França por questões territoriais e dinásticas, com duração de 116 anos.

Revista Vernáculo n. ${ }^{\circ} 40$ - segundo semestre /2017

ISSN 2317-4021 
saudável, Henrique foi uma força de governo bastante fraca e impotente ${ }^{7}$. (JONES, 2015, n.p., tradução nossa).

Devido a essa deficiência, Ricardo Plantageneta foi apontado como regente, enquanto o rei estava incapacitado. Porém, outras pessoas que apoiavam o monarca foram essenciais para manter seu reinado, como Margarida de Anjou, sua esposa, e William de la Pole, $1^{\circ}$ duque de Suffolk. Henrique VI retornou ao poder.

Ricardo III observou seu pai movimentar exércitos com o objetivo de retomar o poder e iniciar um governo de Yorks. Como dito, sua família tinha sangue real. Tanto York quanto Lancaster baseavam suas pretensões ao poder no fato de ambas serem descendentes do rei Eduardo III. Eduardo teve 11 filhos, dentre eles João de Gaunt, duque de Lancaster, sendo sua família representada pela rosa vermelha ${ }^{8}$, e Edmundo de Langley, duque de York, com a representação pela rosa branca.

Henrique VI, Lancaster, e Ricardo Plantageneta, York, se enfrentaram em batalhas durante a segunda metade do século $\mathrm{XV}$, até a vitória do rei em Wakefield, em 1460. Os filhos de Ricardo e sua

\footnotetext{
7 "He became completely helpless, remove from both wit and the world around him to the point of total vacuity. He recognized no one. He could not speak or respond in any way to questions. He could neither feed nor clean himself, since he had no control of his arms or legs and could not even keep his head up. He had no sense of time. No physician could stir him. No medicine could stimulate him. (...) Henry was simply mute and inert: a kingly nothing. Even when sane, Henry had been a fairly weak and impotent force in government."

${ }^{8}$ A atribuição da rosa vermelha aos Lancaster é posterior às guerras, sendo adotada por Henrique VII à época de seu casamento com Elizabeth de York.
} 
mulher, Cecília, foram presos. Pela participação na guerra contra o rei, o duque de York foi considerado traidor e decapitado. Contudo, o conflito entre as famílias não terminou. Eduardo, filho mais velho de Ricardo Plantageneta, assumiu a liderança da causa York após a morte do pai. Conseguiu assumir a coroa em 1461, tornando-se o rei Eduardo IV (1461-1470; 1471-1483). Manteve-se no poder até 1470, quando Henrique VI conseguiu retornar ao trono. Eduardo IV finalmente derrotou o monarca Lancaster na Batalha de Tewkesbury, em 1471, e o aprisionou na Torre de Londres ${ }^{9}$. Após alguns dias de encarceramento, Henrique VI faleceu, sendo o motivo da morte desconhecido. Alguns afirmam que Eduardo mandou assassiná-lo, como vingança pela morte de Ricardo Plantageneta, outros acreditam que Henrique morreu de melancolia, derivada de seus problemas de saúde preexistentes. Com a morte dos principais herdeiros Lancasters, uma vez que o filho de Henrique VI morrera em Tewkesbury, Eduardo pôde estabelecer um governo de Yorks no trono inglês, como seu pai desejou.

Ricardo III recebeu o título de duque de Gloucester aos 9 anos e, desde então, começou a participar da política, ajudando seu irmão a tomar o poder e, posteriormente, a governar. Tornou-se um importante líder militar, apesar de suas dificuldades físicas, um dos aspectos mais questionados sobre sua figura. Appleby et al., cientistas da Universidade de Leicester e responsáveis pelas análises dos ossos de

${ }^{9}$ A Torre, uma das principais construções inglesas, era utilizada tanto como prisão como para residência da realeza, principalmente durante a coroação. 
Ricardo, feitas em 2012, descrevem-no: "o indivíduo é do sexo masculino, com uma composição delicada, entre o fim da segunda e o fim da terceira década de vida, compatíveis com a idade de morte conhecida de Ricardo, aos 32. Ele tinha grave escoliose idiopática, que iniciou em sua adolescência ${ }^{10 "}$. (APPLEBY et al., 2013, p. 536, tradução nossa). Portanto, confirma-se que, de fato, o futuro monarca sofrera de uma deficiência física na coluna.

Em 1483, após 12 anos de governo, Eduardo IV morreu de causas desconhecidas. Criou-se um novo problema dinástico na Inglaterra. Os filhos do rei eram crianças: Eduardo, príncipe de Gales, e Ricardo de Shrewsbury, 12 e nove anos, respectivamente. Havia a preocupação referente à regência e tutela do futuro rei, uma vez que Eduardo era menor de idade. Era necessária sua coroação, para que fosse mantido o reinado no poder dos Yorks e não houvesse novas disputas pela coroa. Contudo, havia discordâncias em relação à necessidade de uma regência ou a admitir que Eduardo fosse considerado adulto.

O duque de Gloucester, após a morte de Eduardo, se tornou um dos homens mais importantes da Inglaterra. Parente mais próximo do jovem Eduardo V, assumiu a posição de regente, apesar da forte pressão para a independência política do sobrinho. Ricardo adiou a coroação, a fim de continuar no poder. Como Dan Jones explica, ele conseguiu

\footnotetext{
10 "The individual is male, with a gracile build, in his late 20s to late 30 s, compatible with Richard's known age at death of 32 . He had severe idiopathic adolescent-onset scoliosis."
} 
assumir o trono para si devido às suspeitas em relação à legitimidade de seus sobrinhos:

No domingo, 22 de junho, o teólogo Dr. Ralph Shaa apareceu na Catedral Paul's Cross para pregar a extraordinária - e especialmente sagrada - mensagem de que o casamento de Eduardo IV com Elizabeth Woodville foi contraído enquanto Eduardo já havia acordado se casar com outra pessoa: Lady Eleanor Butler, a filha do grande soldado lancastriano John Talbot, earl de Shrewsbury. Baseado nisso, Shaa argumentou que Eduardo $\mathrm{V}$ e Ricardo, duque de York, eram ilegítimos e, portanto, Eduardo $\mathrm{V}$ não poderia assumir o trono . Ricardo, duque de Gloucester (...) deveria tomar o trono no lugar de seus sobrinhos. ${ }^{11}$ (JONES, 2014, n.p., tradução nossa).

E assim o fez. Em 1483, Ricardo III assumiu a coroa e se declarou rei da Inglaterra, sob direito legítimo, sendo o herdeiro mais próximo de seu irmão, Eduardo IV.

O governo de Ricardo foi breve. Encontrou bastante resistência, principalmente dos Lancasters, que, apesar de terem sido derrotados, ainda questionavam o poder. Surgiu neste momento a figura

11 "On Sunday 22 June the theologian Dr. Ralph Shaa appeared at St. Paul's Cross to preach the extraordinary - and wholly specious - message that Edward IV's marriage to Elizabeth Woodville had been undertaken while Edward was already contracted to marry someone else: Lady Eleanor Butler, the daughter of the great lancastrian soldier John Talbot, earl of Shrewsbury. On these grounds, Shaa argued, Edward V and Richard, duke of York were illegitimate and therefore the former could not be allowed to take the throne. Instead, Richard, duke of Gloucester (...) should take the throne in the place of his nephews". 
de Henrique, conde de Richmond, filho de Edmundo Tudor e Margarida Beaufort. Por ser descendente de João de Gaunt, por parte de mãe, Henrique tornou-se um forte candidato Lancaster ao trono inglês. Seria o recomeço das disputas dinásticas.

Uma campanha contra Ricardo iniciou-se a partir do sumiço de seus sobrinhos, que estavam presos na Torre de Londres, a mando do rei. Rumores sobre os assassinatos dos príncipes se espalharam e contribuíram para uma construção negativa da imagem de Ricardo III. Mas não há provas de sua participação. Até os dias atuais, pouco se sabe sobre o destino de Eduardo $\mathrm{V}$ e de seu irmão Ricardo. A teoria mais provável seria que o rei tenha ordenado suas mortes. Há aqueles que acreditam na participação do Duque de Buckingham, aliado do monarca, que teria eliminado as crianças para que não existisse questionamento em relação à legitimidade do governo de Ricardo. Uma teoria menos comum acusa Henrique Tudor de ter orquestrado o sumiço, "(...) como uma manobra para remover alguns obstáculos significativos para sua própria reivindicação ao trono ${ }^{12 " ~(B I N G H A M, ~}$ 2014, n.p., tradução nossa).

Nunca comprovado, mas o desaparecimento dos príncipes tornou-se um dos maiores problemas para Ricardo. Muitos distanciavam-se do monarca, apoiando a causa de Henrique. Apesar de ter o apoio do Norte, principalmente York, o rei buscava cada vez mais

\footnotetext{
12 "(...) as a way of removing some significant obstacles to his own claim to the throne."
} 
sedimentar seu reinado, através da hereditariedade. Ricardo III era casado com Anne Neville, filha do importante conde de Warwick, "O Fazedor de Reis". Warwick foi responsável pela ascensão de Eduardo IV, assim como pelo retorno de Henrique VI ao poder. Morreu em batalha e, sem ter herdeiros homens, deixou sua fortuna para as filhas Isabel e Anne.

Juntos, Ricardo e Anne tiveram um filho, Eduardo de Middleham, príncipe de Gales, que morreu aos dez anos de idade por causas desconhecidas. A rainha também faleceria no ano seguinte, em 1485. Como John Ashdown-Hill explica, devido à morte da rainha e de seu filho, para a estabilidade do país e da casa York, cabia ao rei buscar, com urgência, uma nova consorte, para que pudessem gerar herdeiros (ASHDOWN-HILL, 2013, n.p.). Mas Ricardo tinha problemas maiores que a sucessão. Henrique Tudor avançava e conseguia cada vez mais apoio.

Ricardo III e Henrique Tudor se enfrentaram na famosa Batalha de Bosworth, em 1485. Apesar do monarca ter um contingente maior de soldados, foi traído pela participação do exército de Lorde Stanley, que no momento da batalha esperava para decidir qual lado apoiaria. Escolheu Henrique e, desse modo, Ricardo, apesar de ter mais experiência militar que o rival, foi derrotado. Este fato foi imortalizado pela peça de William Shakespeare Ricardo III, publicada em 1592/1593. Na cena IV do quinto ato, o rei, durante a batalha, clama: "apostei minha vida em um lance, aceito o que marcaram os dados. 
Acho que tem seis Richmonds no campo de batalha; cinco deles eu já matei hoje, em vez dele mesmo. Um cavalo! Um cavalo! Meu reino por um cavalo!" (SHAKESPEARE, 2010, p. 186).

O monarca Plantageneta morreu durante a batalha, vítima de um golpe na cabeça. Appleby et al. descrevem o estado dos ossos de Ricardo III:

Dois grandes ferimentos na nuca, compatíveis com golpes de uma alabarda e de uma espada, foram provavelmente fatais. Um terceiro ferimento penetrante, menor, no topo da cabeça é mais enigmático, mas pode ter sido causado por uma pancada de um objeto pontudo, como uma adaga, no alto da cabeça. Outros ferimentos foram mais superficiais e nenhuma das lesões no crânio poderiam ser infligidas em alguém que usasse capacete do tipo mais comum no final do século XV. Dois ferimentos, um corte na costela direita e outro na pélvis direita, típico de golpe através da nádega direita, são, novamente, improváveis de terem sido infligidos em alguém que utilizasse armadura. Estes, juntamente com os dois ferimentos no rosto, podem ser 'lesões de humilhação', feitas após a morte. ${ }^{13}$ (APPLEBY et al., 2013, p. 536, tradução nossa).

\footnotetext{
13 "Two large wounds underneath the back of the skull, consistent with a halberd and a sword blow, are likely to have been fatal. A third, smaller, penetrating wound to the top of the skull is more enigmatic, but may have been caused by a sharp blow from a pointed weapon, such as a dagger, on the crown of the head. Other wounds were more superficial and none of the skull injuries could have been inflicted on someone wearing a helmet of the type favoured in the late fifteenth century. Two wounds, a cut on a right rib and a cut to the right pelvis typical of a thrust through the right buttock,
} 
Seu corpo foi enterrado no mosteiro Greyfriars, na cidade de Leicester, sem honras para um antigo rei da Inglaterra. Henrique, conde de Richmond, tornou-se Henrique VII (1485-1509), primeiro da dinastia Tudor, e se casou com Elizabeth de York, filha de Eduardo IV, estabelecendo uma união entre a rosa vermelha de Lancaster e a branca de York.

Henrique VII tinha menos reivindicação ao trono do que Ricardo III. Os Tudors descendiam do casamento de João de Gaunt com sua amante, Katherine Swynford, que mais tarde se tornou rainha consorte. Apesar do decreto que tornou legítimos os filhos prévios ao casamento, este também estabeleceu que nenhum de seus descendentes poderia ser rei. Apesar da legitimidade ter sido uma questão menos importante durante as Guerras, tornou-se fundamental durante o reinado dos Tudors. Esta busca por legitimação é vista, principalmente, no governo de Henrique VIII (1509-1547), que executou os últimos Plantagenetas da Inglaterra para que não houvesse contestação em relação ao seu reinado e sua dinastia.

Os Tudors, ao invés de utilizarem suas linhagens e dependerem de seus ascendentes, mantiveram seus governos ao se basearem na vontade de Deus, um dos princípios do absolutismo. Como explica Jane Bingham, "graças à providência divina, como os advogados de

are again unlikely to have been inflicted on someone wearing armour. These, along with two wounds to the face, may be 'humiliation injuries' delivered after death." 
Henrique afirmavam, o novo rei havia libertado o povo inglês da tirania de Ricardo de York ${ }^{14 "}$ (BINGHAM, 2012, n.p., tradução nossa).

As ações dos Tudors, desde a fundação até o período elisabetano, não são julgadas do mesmo modo como o pequeno reinado de Ricardo é descrito. Mas a História é favorável àqueles que a escreveram primeiro. Portanto, cabe uma análise daqueles que registraram o triunfo Tudor e a decadência Plantageneta, como as Crônicas de Holinshed, objeto de estudo deste artigo.

\section{As Crônicas de Holinshed}

"E assim ele ensinou a outros como executar a justiça e equidade, o contrário do que praticava diariamente ${ }^{15 "}$ (HOLINSHED, 1587, n.p.). Desse modo se inicia a descrição do governo de Ricardo III nas Crônicas de Holinshed. Publicadas nos anos de 1577 e 1587, foram uma das principais fontes históricas responsáveis pela criação da imagem negativa de Ricardo III. Construídas por um conjunto de pessoas, tiveram na figura de Reyner Wolfe seu idealizador, este desejando a criação de uma história completa e universal. Contudo, após sua morte antes das publicações, seu assistente, Raphael Holinshed, terminou o projeto, relatando somente a história da

\footnotetext{
14 "Thanks to the heavenly providence, Henry's lawyers claimed, the new king had delivered the English people from the tyranny of Richard of York". Jane Bingham se refere ao rei Ricardo III, duque de Gloucester, da família York. Ricardo, duque de York, também conhecido como Ricardo Plantageneta, foi seu pai, que reivindicou a coroa de Henrique VI.

15 "And thus he taught other to execute iustice and equitie, the contrarie whereof he dailie exercised."
}

Revista Vernáculo n. ${ }^{\circ} 40$ - segundo semestre /2017

ISSN 2317-4021 
Inglaterra, Escócia e Irlanda (THE HOLINSHED PROJECT, 2015, n.p.).

A edição de 1577 contém 4 volumes, dos quais o primeiro e o quarto tratam da história da Inglaterra. O primeiro descreve o país, seus rios, metais e construções, além da cronologia de reinados e personagens importantes. O quarto volume, como dito no prefácio, surgiu devido ao tamanho da obra e contém a descrição dos anos em que William, o Conquistador (1066-1087) governou o país até Elizabeth I (1558-1603). Já a edição de 1587, utilizada como fonte neste artigo, contém informações extras, divididas em 6 volumes. Apesar de Holinshed já ter falecido quando esta edição foi criada, as Crônicas ainda levaram seu nome devido ao sucesso da primeira publicação.

Sendo uma crônica do século XVI, os autores consultaram textos de pessoas das épocas que descreviam. Um dos relatos utilizados foi A história do rei Ricardo III, de Thomas More, escrito por volta de 1513 e publicado pela primeira vez em 1543. O autor ficou famoso na história pela publicação do livro A Utopia e por ter sido chanceler de Henrique VIII, segundo da dinastia Tudor. Foi morto pelo monarca por criticar a Reforma Protestante ocorrida na Inglaterra e por não apoiá-lo em sua decisão de divorciar-se da rainha Catarina de Aragão.

Apesar das desavenças posteriores, no período da escrita do livro More e Henrique VIII eram próximos. Como súdito, faz sentido que o autor louvasse a dinastia, em detrimento da casa anterior. $\mathrm{O}$ texto descreve a história de Ricardo III, sem necessariamente enfatizar suas 
decisões políticas, mas focando em atos considerados tirânicos. O livro demonstra a parcialidade do autor, como se seu objetivo fosse legitimar a dinastia Tudor, ao criticar o governo e figura de Ricardo. Percebe-se, portanto, que More atribui uma imagem a Ricardo, sem comprometimento com uma escrita que buscasse descrever o reinado do monarca York e tornar-se um estudo histórico.

Essa característica também é presente nos estudos de Holinshed e outros autores do século XVI. É mais perceptível, principalmente, ao analisar o desaparecimento dos filhos de Eduardo IV, momento em que a maioria dos autores acusam Ricardo de ter participação no ocorrido. Como dito, sem comprovação. Nas Crônicas de Holinshed, há a transcrição do texto de More sobre as mortes:

Então todas as outras coisas foram removidas deles (dos príncipes), este Miles Forest, e John Dighton, por volta de meia-noite (as inocentes crianças deitadas em suas camas) entraram nos quartos e de repente, prendendo-os em suas roupas, para que ficassem envolvidos e enredados, mantendo-os deitados ao forçarem os travesseiros e camas de penas em suas bocas, assim, com o tempo, sufocados e duros, suas respirações falhando, entregaram suas inocentes almas para Deus, para a felicidade dos céus, deixando o tormento de seus corpos na cama ${ }^{16}$. (HOLINSHED, 1587, n.p., tradução nossa).

\footnotetext{
16 "Then all the other being remooued from them, this Miles Forrest, and Iohn Dighton, about midnight (the séelie children lieng in their beds) came into the chamber, \& suddenlie lapping them vp among the clothes, so to bewrapped them and
} 
Segundo as Crônicas, não havia nada que fosse tão simples e tão provado como a participação de Ricardo no sumiço de seus sobrinhos, ou até mesmo em seus assassinatos, mas ainda haviam aqueles que suspeitavam disso. Devido a esse fato, Holinshed descreve o ato, segundo o que escutou, considerando que deve ter sido verdade (HOLINSHED, 1587, n.p.).

O maior problema dos textos, tanto no livro de More quanto no de Holinshed, é a aproximação com a ficção. São escritos a partir de relatos e, no caso das Crônicas, com quase 100 anos de diferença. Os dois autores apresentam aquilo que acreditam ser verdade, o que foi comumente passado e, no caso da figura de Ricardo III, aquilo que possivelmente foi construído para legitimar a nova dinastia. Os livros não são isentos de opinião. Deixam bem claro as preferências em relação aos monarcas e suas decisões, assim como os julgamentos de suas índoles. O monarca Plantageneta pode ter sido, de fato, um tirano. Mas deve-se levar em consideração a possibilidade de que suas ações tenham sido exacerbadas para que o novo rei fosse visto como uma melhor opção. Como relatado, Henrique VII não possuía uma forte reivindicação ao trono.

Apesar de tais preocupações, as crônicas são importantes fontes históricas para os historiadores atuais. Principalmente após a

intangled them, kéeping downe by force the fether-bed and pillows hard vnto their mouths, that within a while, smoothered and stifled, their breath failing, they gaue up to God their innocent soules into the ioies of heauen, leauing to the tormentors their bodies dead in the bed."

Revista Vernáculo n. ${ }^{\circ} 40$ - segundo semestre /2017

ISSN 2317-4021 
Escola dos Annales, movimento historiográfico iniciado em 1929, que buscou introduzir novos objetos de pesquisa para a História, assim como a renovação daqueles já disponíveis. Como Luiz Antônio Gloger Maroneze escreve, a crônica:

[...] pode ser percebida como uma forma privilegiada de narrar o vivido, pois entre o fato e a ficção, ela abre portas especiais para acessar a sociedade contemporânea: o gênero menor da literatura assume, dessa forma, um espaço privilegiado na reflexão histórica (MARONEZE, 2014, p. 2).

O estudo das Crônicas de Holinshed nos possibilita o entendimento do pensamento do século XVI, particularmente do período elisabetano, e, desde seu contexto de criação, o texto foi utilizado como fonte histórica. Na peça Ricardo III, em que Shakespeare retrata o monarca como uma pessoa avarenta e sedenta de poder, o dramaturgo inglês utilizou o relato de Holinshed sobre a aparência física de Ricardo para criar o vilão que precisava. Holinshed caracteriza o rei como de "(...) pequena estatura, traços doentios nos membros, corcunda, com o ombro esquerdo mais elevado que o direito (...) $)^{17 " ~(T H E ~ H O L I N S H E D ~ P R O J E C T, ~ 2015, ~ n . p ., ~ t r a d u c ̧ a ̃ o ~ n o s s a) . ~ A ~}$ partir desta informação, no primeiro ato, cena 1 , o personagem de Ricardo, então duque de Gloucester, se define:

17 "(...) litle of stature, ill featured of limmes, crooke backed, his left shoulder much higher than his right (...)"

Revista Vernáculo n. ${ }^{\circ} 40$ - segundo semestre /2017

ISSN 2317-4021 
Mas eu, que não fui moldado para as proezas dessas brincadeiras, nem fui feito para cortejar espelho de olhar amoroso; eu, que sou rude estampa e sou aquele a quem falta a grandeza do amor para me pavonear diante de uma ninfa de andadura lúbrica; eu, que fui deserdado de belas proporções, roubado de uma forma exterior por natureza dissimuladora, foi com deformidades, inacabado e antes do tempo que me puseram neste mundo que respira, feito mal e mal pela metade, e esta metade tão imperfeita, informe e tosca que os cachorros começam a latir para mim se me paro ao lado deles. (SHAKESPEARE, 2010, p. 25-26).

Por anos, a Richard III Society ${ }^{18}$, comunidade que estuda e pesquisa a vida do monarca e responsável por defender sua imagem, negou tais afirmações de deformidades, pois a associam à negatividade em relação ao rei. Contudo, após a descoberta dos ossos de Ricardo, percebeu-se claramente a curvatura da coluna. Portanto, as definições feitas por Shakespeare e Holinshed, em parte, estavam corretas. Mas a deficiência de Ricardo não o torna um vilão, assim como sua negação por parte dos ricardianos ${ }^{19}$ não o faz um santo.

Tais relatos já revelam a tendência de Holinshed a criticar o governo e a figura de Ricardo. Percebe-se que são julgamentos de caráter, afirmações que não se baseiam completamente em fatos ou eventos específicos. É a tendência comum do texto, exemplificar o

\footnotetext{
${ }^{18}$ Ver http://www.richardiii.net/

${ }^{19}$ São pessoas que defendem a figura e governo de Ricardo III, assim como publicam textos favoráveis ao rei.
} 
monarca inglês como aquele que engana, conspira, assassina. Levando em consideração o contexto de guerra e necessidade de legitimação do governo, é possível que ele de fato tenha sido assim. Contudo, sem fatos para comprovarem tal comportamento.

Quando Holinshed descreve a coroação de Ricardo e aqueles que o apoiaram, fica mais clara essa conjectura sobre a personalidade do rei. O autor afirma que, ao tomar o poder para si, apresentando uma "clemência enganadora", o Plantageneta conquistou juristas e nobres ao perdoar quaisquer ofensas cometidas contra ele, prometendo esquecer as inimizades existentes no reino. Em seguida, Holinshed define que isso não ocorreu, pois "como coisas maliciosas nunca são bem guardadas, em todo o tempo de governo, nunca parou com mortes cruéis e massacres $^{20 "}$ (HOLINSHED, 1587, n.p.). Por que não poderia ser verdade o perdão? E por que a atribuição de "enganadora"? Outros reis da história inglesa perseguiram seus inimigos ao assumirem o poder, como o próprio Henrique VII, tão cultuado pelo autor. De fato, os Tudors assassinaram a maioria dos Plantagenetas que poderiam ameaçar seus reinados, como no caso da Condessa de Salisbury. Sobrinha de Eduardo IV e tia do rei Henrique VIII, foi uma das mais nobres mulheres do século XVI. Foi acusada de traição, falsamente, e decapitada na Torre de Londres.

\footnotetext{
20 "And as the thing euill gotten is neuer well kept, thorough all the time of his reigne neuer ceassed there cruell death and slaughter (...)"
} 
Outro momento em que Ricardo é julgado diz respeito à morte de sua esposa, Anne, quando Holinshed atribui ao rei mais um assassinato. Afirma que o monarca desejava se casar com sua sobrinha, Elizabeth de York, uma vez que haviam rumores sobre a possibilidade dela se unir a Henrique Tudor. Pelo fato da rainha ter adoecido rapidamente, muitos acusaram o rei de tê-la envenenado. Holinshed escreve:

Mas por mais que tenha sido por sorte, seja por pensamento interior e meditação do coração, ou por ingestão de veneno (o que é dito como mais provável) em poucos dias, a rainha partiu de sua vida transitória, e foi enterrada solenemente na Igreja de St. Peter em Westminster. (...) O rei assim (de acordo com seu intenso desejo) saiu dos laços matrimoniais e começou a lançar uma fantasia tola para sua sobrinha, Lady Elizabeth, fazendo muitos pedidos para que ela se juntasse a ele em um matrimônio legal ${ }^{21}$. (HOLINSHED, 1587, n.p., tradução nossa).

Esta ideia de envenenamento é aceita principalmente por historiadores que concordam com a visão negativa de Ricardo, pois afirmam que este se casou com Anne por interesses políticos e

\footnotetext{
21 "But howsoeuer that it fortuned, either by inward thought and pensiuenesse of hart, or by infection of poison (which is affirmed to be most likelie) within few daies after the quéene departed out of this transitorie life, and was with due solemnitie buried in the church of S. Peter at Westminster. (...) The king thus (according to his long desire) losed out of the bonds of matrimonie, began to cast a foolish fantasie to ladie Elizabeth his néece, making much sute to haue hir ioined with him in lawfull matrimonie."
} 
econômicos, já que os Nevilles eram uma das mais ricas famílias da Inglaterra. Novamente, nada novo, pois era a prática comum da nobreza. Porém, como John Ashdown-Hill escreve, o rei sentia afeição pela esposa. $\mathrm{O}$ autor explica:

Não há razão para duvidar da afeição de Ricardo por Anne Neville, e em um de seus últimos atos antes da morte da rainha, em um momento em que seu falecimento era esperado a qualquer hora, foi doada uma quantia de $£ 300$ à universidade que, no ano anterior, havia decretado uma missa anual para a "felicidade do rei" e para sua "querida rainha consorte Anne 22" (HALSTED apud ASHDOWNHILL, 2013, n.p.).

Torna-se claro que qualquer ação de Ricardo era vista como uma manipulação, esquema, maldade de sua parte. Até mesmo atos que não eram de seu controle, como a morte da rainha, mais atribuída à tuberculose ou ao câncer.

Holinshed termina sua descrição do reinado de Ricardo dizendo que sua morte foi justamente merecida e a mais esperada. Escreve: "assim terminou este príncipe sua vida mortal com infâmia e

\footnotetext{
22 "There is no reason to doubt Richard's affection for Anne Neville, as one of his last acts prior to the queen's decease, and at a time when her dissolution was hourly expected, was reportedly a grant of $£ 300$ to that university which in the preceding year had decreed an annual mass for "the happy state" of the king and 'his dearest consort, Anne'."
} 
desonra, que nunca preferiu fama ou honestidade antes de ambição, tirania e prejuízo"23 (HOLINSHED, 1587, n.p., tradução nossa).

Usurpador, tirano, assassino. Essas são as características utilizadas por Holinshed e imortalizadas por Shakespeare. Até os dias atuais, muito se discute sobre a personalidade de Ricardo e se seus atos são tão vilanescos a ponto de atribuírem ao rei o título de pior e mais controverso monarca inglês.

\section{Considerações finais}

$\mathrm{O}$ presente artigo teve como objetivo desmitificar a imagem do rei Ricardo III da Inglaterra e apresentar sua vilanização a partir das Crônicas de Holinshed, de 1587.

Em muitos estudos, historiadores se prendem a dicotomias como bom-mau, inocente-vilão. Ricardo III é símbolo disso. Encontram-se pesquisas que tentam torná-lo o melhor monarca inglês, classificando-o como gentil, ou aquelas que o denominam assassino, esquecendo de seu reinado e importância na história. Ambas as pesquisas descritas estão equivocadas, devido às suas parcialidades. Ricardo III não foi diferente de outros monarcas da Inglaterra. Tomou o poder para si, assim como seu sucessor, Henrique VII. Atribuem a ele a morte de seus sobrinhos. Possível, porém nunca comprovado. Há registros de outros reis da Inglaterra que mandaram executar esposas,

23 "Thus ended this prince his mortall life with infamie and dishonor, which neuer preferred fame or honestie before ambition, tyrannie and mischiefe." 
como Henrique VIII, e estes são cultuados pelas artes e por suas decisões políticas.

Consideradas como um importante projeto de pesquisa e contribuição para a construção da história do país, as Crônicas foram utilizadas por várias pessoas que desejavam ter conhecimento dos acontecimentos anteriores à sua geração. De fato, o texto é uma importante representação do pensamento inglês do século XVI, assim como da noção de construção histórica do período. Porém, é tendenciosa. Foram criadas durante o governo de Elizabeth I, Tudor, a dinastia que retirou Ricardo III do poder.

Espera-se que outros estudos surjam a partir da recente descoberta dos ossos do rei Plantageneta, uma vez que a discussão em torno de sua imagem tem crescido. Estudos estes que considerem os fatos, que não atribuam julgamentos, muito menos deixem suas preferências pessoais ditarem a imagem de uma figura histórica significativa como Ricardo III.

\section{Referências}

\section{Fontes}

AS CRÔNICAS DE HOLINSHED. Richard the ThirdN 2. ed. 1587.

Disponível em: <http://www.gutenberg.org/files/45611/45611-h/45611h.htm> Acesso em: 10 ago. 2015. 
THE HOLINSHED PROJECT. The history of king Edward the fifth, and king Richard the third unfinished, written by master Thomas

More.

Disponível

em:

http://www.english.ox.ac.uk/holinshed/texts.php?text1=1587_6205> Acesso em: 15 out. 2015.

\section{Bibliografia}

APPLEBY, J.; BUCKLEY, R.; FOXHALL, L. et al. 'The king in the car park': new light on the death and burial of Richard III in the Greyfriars church, Leicester, in 1485. Antiquity, v. 87, n. 336, p. 519$538,2012$.

ASHDOWN-HILL, John. The last days of Richard III and the fate of his DNA. Gloucestershire: The History Press, 2013 (versão digital).

BINGHAM, Jane. The kings and queens of England's golden age. Londres: Arcturus, 2012 (versão digital).

HALSTED, Caroline Amelia. Richard III. London: Longman, Brown, Green, and Longmans, 1844.

JONES, Dan. The Hollow Crown: the Wars of the Roses and the rise of the Tudors. 1. ed. London: Faber \& Faber, 2014 (versão digital).

MARONEZE, L. A. G. A crônica e o fazer histórico na crise da modernidade: reflexões e possibilidades. Estudos históricos, Uruguai, ano VI, n. 12, jul. 2014. Disponível em: 
http://www.estudioshistoricos.org/12/artigo\%20cronica\%20e\%20hist.p df < Acesso em: 15 out. 2015.

SHAKESPEARE, William. Ricardo III. Tradução Beatriz Vigas Faria. Porto Alegre: LP\&M, 2010.

The making of the chronicles. Disponível em: http://www.cems.ox.ac.uk/holinshed/chronicles.shtml\#two. Acesso em: 10 set. 2015.

Recebido em 24/05/2017, aceito para publicação em 16/07/2017 